110

日本機械学会論文集 $(\mathrm{B}$ 編)

論文 No. 08-0576

75 巻 749 号 (2009-1)

\title{
流量変動を受ける動圧浮上血液ポンプの動特性と安定性*
}

\author{
中 村 陽 -.*1, 塚 本寛*2
}

\section{Dynamic Characteristics and Stability of a Centrifugal Blood Pump with Hydrodynamic Levitation under Flow Fluctuation}

\author{
Yoichi NAKAMURA*3 ${ }^{* 3}$ and Hiroshi TSUKAMOTO \\ ${ }^{* 3}$ Department of Biological Functions and Engineering, Kyushu Institute of Technology, \\ 2-4 Hibikino, Wakamatsu-ku, Kitakyushu-shi, Fukuoka, 808-0196 Japan
}

\begin{abstract}
In this paper, we describe the stability of a centrifugal blood pump with hydraulic levitating bearings in pulsatile flow, since the ventricular assist device (VAD) set downstream of heart is affected by the pulsation. The test pump was developed for VAD using conical spiral groove bearings. The flow through the pump was excited from 0.25 to $3.0 \mathrm{~Hz}$ by oscillator driver in the circulatory system. The rotational speed, flow rate, total pressure rise and displacement of rotor from casing center were measured to study stability of test pump. The stability test was done for the whirling motion of impeller and the conditions for stability of the blood pump were determined by the dynamic characteristics test. The results showed increasing whirling motion with increasing fluctuating frequency.
\end{abstract}

Key Words: Unsteady Flow, Turbomachinery, Fluid Machinery, Stability, Fluid Force, Blood Pump, Artificial Heart, Whirling Motion, Dynamic Characteristics

\section{1. 序}

近年の血液ポンプには，小型化・高性能化の容易な ターボ式の血液ポンプが多く開発されている.これは, 血栓の発生原因となるシール部を持たない非接触の磁 気浮上軸受 ${ }^{(1)}$ (3)や, 動圧浮上軸受 ${ }^{(4)(5)}$ O)採用により, 長期間の運用に耐えられるようになったためである. 特に, 動圧浮上軸受を用いた血液ポンプは, 磁気軸受 を用いたものに比べ，外部電力を必要とせず，メンテ ナンスフリーであるため, 長期の体内埋め込みに有利 である. しかし，動圧浮上軸受は，羽根車自体が回転 しなければ非接触保持が出来ず, 低い回転速度では保 持力が低下寸るため, 羽根車は不安定な状態に陷る. また, 補助心臟として用いられる血液ポンプは，心臓 と直列に配置されることが多く，心臓が発する流量変 動の影響を受ける.そのため, 血液ポンプでは, ポン プ性能としての安定性と羽根車運動としての安定性の 両方を把握しておく必要がある.

\footnotetext{
* 原稿受付 2008 年 6 月 24 日.

*1 正員, 九州工業大学大学院生命体工学研究科(画 808-0196 北九州市若松区ひびきの 2-4).

*2 正員, フェロ一, 九州工業大学大学院生命体工学研究科.

E-mail : nakamura-youichi@edu.life.kyutech.ac.jp
}

従来の血液ポンプに関する研究では, 基本的なポン プ性能や血液に対する変性についての研究が中心であ り，血液ポンプの動特性や流体力について調べている ものは少ない，動的な性能に関しては，Yoshino and Akamatsu ${ }^{(1)}$ がポンプの回転速度変動下で抵抗やコンプ ライアンスに着目してポンプ非定常特性を理論的・実 験的に調べている。しかし，供試ポンプが磁気浮上型 であり，回転速度で保持力の変化する流体浮上型に対 してその結果の流用の適否は不明である.

その他の研究は，ポンプシステムの自励振動時の羽 根車の挙動に関する考察 ${ }^{(3)}$ 衤が主であり, 流量変動下 でのポンプ性能の安定性を調べたものはない．

本研究では，動圧浮上軸受の一種であるコニカルス パイラルグルーブ軸受をもつ遠心型血液ポンプを試作 し，羽根車運動およびポンプ動特性を調べた，動特性 試験装置によって，ポンプ流量を正弦状に変動させ， ポンプ出入口圧力や流量の時系列データに伝達マトリ ックス法 (7) (9)を適用してポンプ動特性の安定判別を 行った. 同時に，流量変動を伴う動的条件下での羽根 車運動の安定性を調べることにより，安全な運転範囲 を調べた。 


\section{2. 記 号}

$A \quad:$ 断面積 $\left[\mathrm{m}^{2}\right]$

$f \quad:$ 强制周波数 $[\mathrm{Hz}]$

$G_{i j} \quad$ : 伝達マトリックス

$g:$ 重力加速度 $\left[\mathrm{m} / \mathrm{s}^{2}\right]$

$H$ ：全揚程 $[\mathrm{m}]$

$h$ : 圧力変動振幅 $[\mathrm{m}]$

$L$ ：代表流線長さ [m]

$L_{e q} \quad:$ 等価管路長 $\left(=\int_{d=0}^{L}\left\{A_{0} / A(x)\right\} d x\right) \quad[\mathrm{m}]$

$N$ ：回転速度 $\left[\mathrm{min}^{-1}\right]$

$P$ : 動力 $[\mathrm{W}]$

$P_{w}:$ 水動力 $[\mathrm{W}]$

$p$ : 圧力 $[\mathrm{Pa}]$

$Q$ : 流量 $\left[\mathrm{m}^{3} / \mathrm{s}\right]$

$t$ : 時間 [s]

$u \quad$ : 羽根車周速度 $[\mathrm{m} / \mathrm{s}]$

$v_{m} \quad$ ：子午面速度 $[\mathrm{m} / \mathrm{s}]$

$x, y$ : A-A 平面座標系 [m] (図 1)

$Z_{p} \quad$ : ポンプインピーダンス $\left[\mathrm{s} / \mathrm{m}^{2}\right]$

$\varepsilon \quad$ : 偏心量 $\left(=\sqrt{x^{2}+y^{2}}\right) \quad[\mathrm{m}]$

$\eta$ : 効率 [式(4) 参照]

$\theta \quad:=\operatorname{Tan}^{-1}(y / x) \quad[\mathrm{rad}]$

$\rho:$ 密度 $\left[\mathrm{kg} / \mathrm{m}^{3}\right]$

$\sigma: \varepsilon$ 標潐偏差 $[\mathrm{m}]$

$\phi \quad$ : 流量保数 [式(3) 参照]

$\psi$ : 揚程倸数 [式(2) 参照]

$\Omega$ : ふれまわり運動回転角速度 [rad/s]

$\Omega / \omega ：$ ふれまわり速度比

$\omega$ ：羽根車の回転角速度，[rad/s] 添字

D ：設計点

d : :ポンプ吐出しロ

M : モータ

$\mathrm{p} \quad:$ ポンプ

qs : 準定常

$\mathrm{s} ：$ ポンプ吸込口

$V \quad:$ 電力計測定值

2 : 羽根車出口

\section{3. 供試ポンプ}

图1 亿供試ポンフ断面図を示寸。供試ポンプは，羽根車 外径が $40 \mathrm{~mm}$ で, 産業用ポンプに隻じて設計された ${ }^{(10)}$.た だし，血栓防止の観点から血液とポンプとの接蝒面積を減
ら寸ため，意四的に流路嘼狭くされている，動王浮上軸 受として， 円錐台面に螺解状の溝を生成したコニカルスパ イラルグルーブ軸受(CSGB)を羽根車の前と後に配した. CSGB は斜面にすべり面か疗在するため, 軸方向と半径方 向を同時呮保でき，その上，構造も単純化できる，軸受 形犬は Muijdeman ${ }^{(11)}$ による実験近似式と予備実唤(10)によっ て決定した

\section{4. 実医装置}

実験装置の概略を図 2 に示寸，供試ポンプは，イン バータで回転制御されたモータにより駆動される。作 動流体怔水で，加振装置に接続された圧力室から，供 試ポンプ，電磁流量計，流量調節弁を経て，リザーバ に戻る閉ループて構成されている. 半導体式圧力変換 器で検出されたポンプ吸込口及び吐出し口の圧力は， アンプにより増幅され，データロガーに記録される。 模擬拍動としての流量変動には，ギアモータにより駆 動されるスライダー・クランク機構を使用し，これ沉 より周波数 $f=3 \mathrm{~Hz}$ までの正弦状の流量変動を発生さ せることが出来る. ポンプ効率の計測には，効率が既 知なモーターの入力電力加二電力計法により求めた

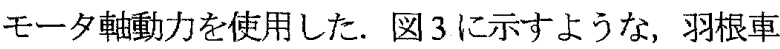
のケーシング中心からの変位 $(x, y)$ は, 渦電流式変位セ ンサにて検出される。図4は，取得されたデー夕波形 の時間履歴を示している.

\section{5. 安定判別法}

入出力の状態量が微小変動している場合，ポンプの 動特性によってはポンプ全体がか加振源となり，ある周 波数において振動振幅が増幅される場合がある。これ は，ポンプの動的な不安定性が管路系の隇衰効果を上 回る場合に生じる，ポンプの動特性を解析寸るには，

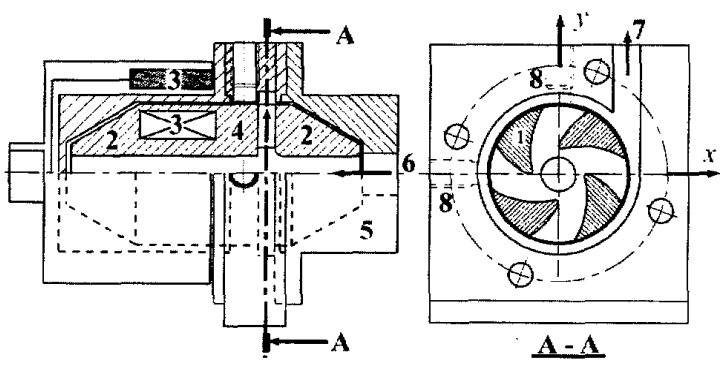

1. Impeller, 2. Conical spiral groove bearing,

3. Coupling magnets, 4. Rotor, 5. Pump casing,

6. Suction port, 7. Dischage port,

8. Eddy current displacement sensor

Fig.1 Cross sectional view and coordinate system of test pump. 
様々な方法があるが，線形系に対しては伝達マトリッ クス法を用いることによって容易に安定判別が可能で ある ${ }^{(7)}$. 伝達マトリックス $G_{i j}$ の $G_{12}$ 項はポンプインピ 一ダンス $Z_{p}$ と呼ばれ，本研究では，次の簡易式 (7)(8) によって求めた.

$$
Z_{p}=\frac{\widetilde{p}_{s}-\widetilde{p}_{d}}{\rho g \widetilde{Q}}=-\frac{\widetilde{H}}{\widetilde{Q}}
$$

ここで, ( )は変動分を表す，変動データには様々な周 波数成分が含まれているが，フーリエ変換法によって 強制周波数成分のみを抽出し，各周波数に対する $Z_{p}$ を算出した， $Z_{p}$ の実部 $\operatorname{Re}\left(Z_{p}\right)$ はポンプレジスタンスと 呼ばれ，この值の正負により動的な安定性を評価でき る $^{(8)}$.

この試験は, 各物理量の線形性が成り立つ範囲で行 われるべきである．動特性試験を行う前に本実験条件 において線形性を満足しているかを確認した。図 5 は,

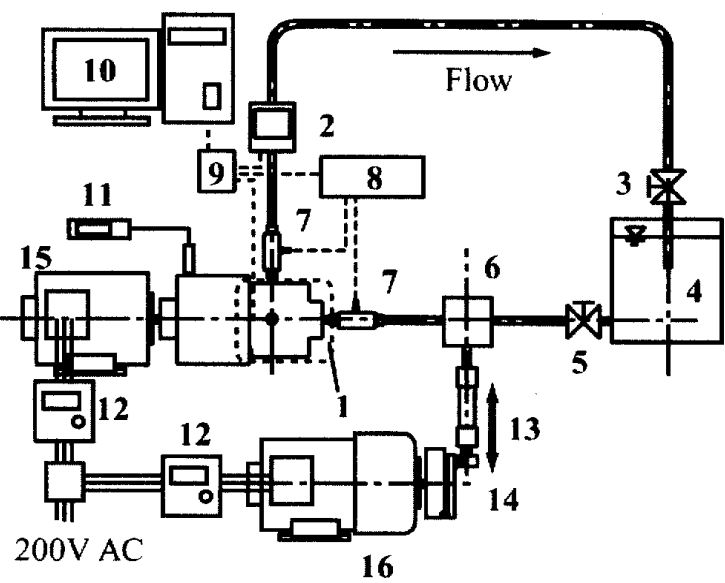

1. Test pump, 2. Electro-Magnetic Flow meter,

3. Control Valve, 4. Reservoir, 5. Gate valve,

6. Pressurization chamber. 7. Pressure sensor,

8. Amplifier, 9. Analog I/O board.

10. Computer, 11. Tachometer, 12.Inverter,

13. Oscillator driver, 14. Slider-Crank mechanism,

15. Motor, 16. Geared motor

Fig. 2 Experimental set up for static and dynamic characteristic test of test pump.

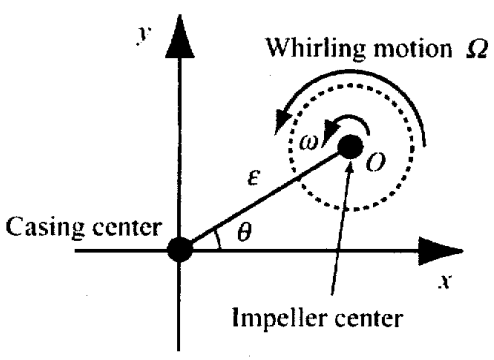

Fig. 3 Coordinate system of impeller.
その結果で，流量変動比に対する変動圧力振幅と変動 流量に詨する圧力の位相差を示している. 図のように,
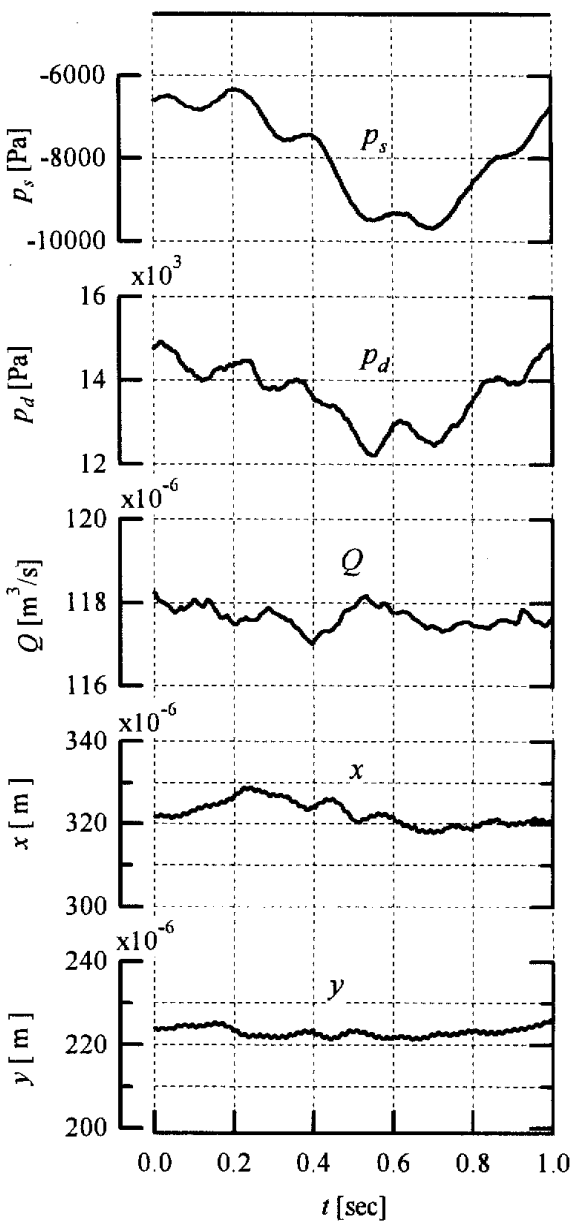

Fig. 4 Time histories of $p_{\mathrm{s}}, p_{\mathrm{d}}, Q, x$, and $y$ $\left(\phi / \phi_{\mathrm{D}}=1.0, N=3000 \mathrm{~min}^{-1}, f=1.0 \mathrm{~Hz}\right)$

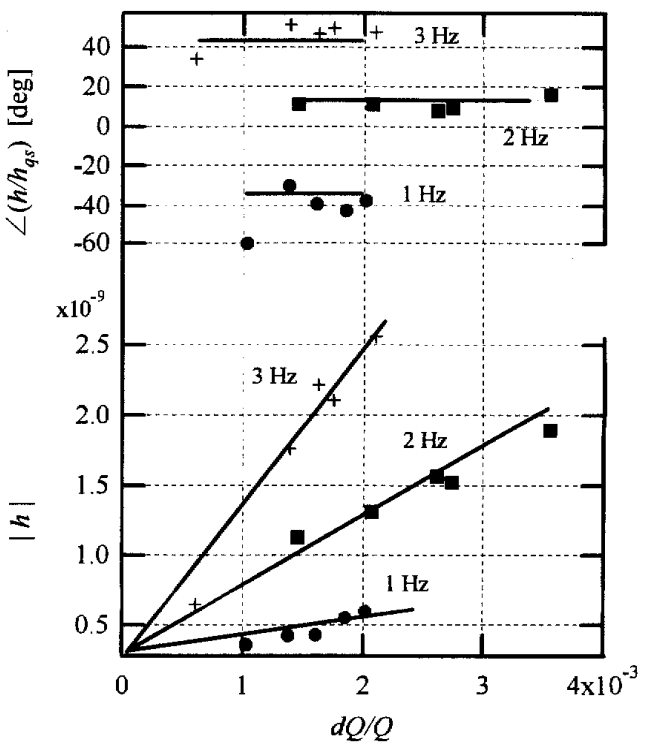

Fig. 5 Dependence of the frequency response on amplitude of fluctuations $\left(\phi / \phi_{\mathrm{D}}=1.0, N=\right.$ $3000 \mathrm{~min}^{-1}$ ). 
本実験の範囲では，線形性が保たれている.

また, 加振機によって強制周波数 $f$ で流量を変動さ せた場合, 測定量には, 管路特性や流体の圧縮性など, 强制周波数以外の影響が考えられる，そこで，図 6で は，流量に対寸る吸込および吐出し圧力， $p_{s}$ および $p_{d}$ と強制周波数 $f$ の相関をコヒーレンスで示している. それぞれが 1 に近い值となっているので, 本試験では, 全強制周波数域で外部の影響を考えることなく加振機 による流量変動との関係を考えてよい.

\section{6. 結 果 と考察}

6・1 棦特性試験 供試血液ポンプの静特性試験 を行い，次式で整理した。

$$
\psi=\frac{H}{u_{2}^{2} / g}
$$

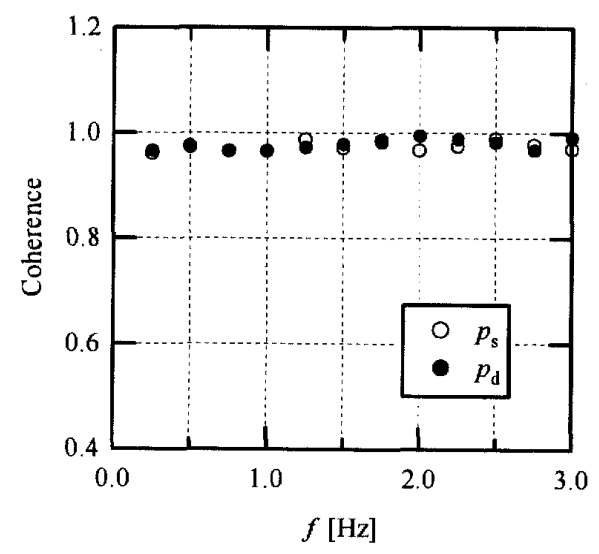

Fig. 6 Coherence function between input $Q$ and output $p_{\mathrm{s}}$ and $p_{\mathrm{d}}\left(\phi / \phi_{\mathrm{D}}=1.0, N=3000 \mathrm{~min}^{-1}\right)$.

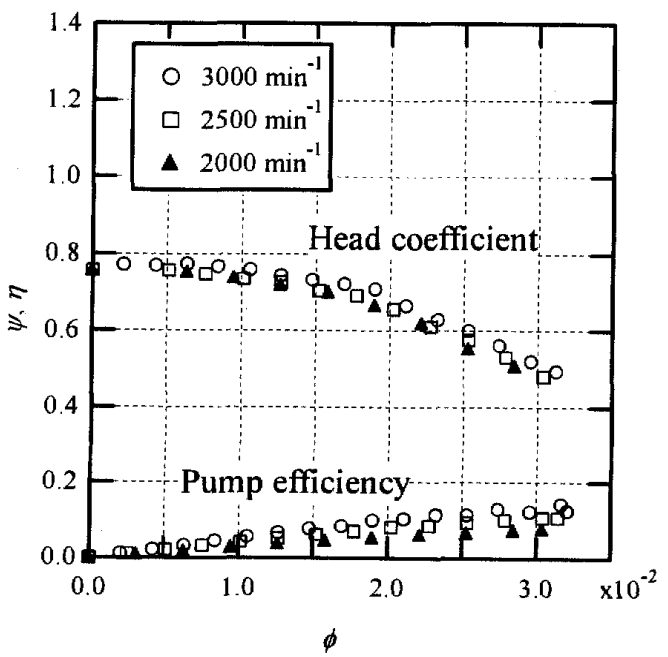

Fig. 7 Pump characteristic of test pump.

$$
\begin{aligned}
& \phi=\frac{v_{m 2}}{u_{2}} \\
& \eta_{p}=\frac{P_{w}}{P_{M}}=\frac{\rho g Q H}{\eta_{M} P_{V}}
\end{aligned}
$$

図7は特性曲線を示している，製作した血液ポンプは 回転速度 $3000 \mathrm{~min}^{-1} \sigma$ 運転条件において，設計流量 5 $\mathrm{L} / \mathrm{min}$ で全揚程 $2.6 \mathrm{~m}(190 \mathrm{mmHg})$, 最大流量は $8 \mathrm{~L} / \mathrm{min}$, 最大全揚程 $3.2 \mathrm{~m}$ ( $233 \mathrm{mmHg}$ )であった．性能曲線は全 流量域で右下がりの傾向を持ち，静的に安定であり， 補助人工デバイスとして，十分利用可能である. ポン プ効率は設計流量付近で 0.14 程度と，市販ポンプに比 ぶて低い值となった。

図 8 は各回転速度での羽根車中心 $O$ の $y$ 方向時間平 均偏心位置とその標準偏差 $\sigma_{\mathrm{y}}$ を示している. 本ポンプ では，羽根車の回転速度を上げると羽根車はふれまわ りながら浮上し，原点より $y=200 \mu \mathrm{m}$ 上方にて偏心す る. また, 回転速度 $N<750 \mathrm{~min}^{-1}$ では, ふれまわりが 大きくなるが，運動は発振することなく，ポンプ自体

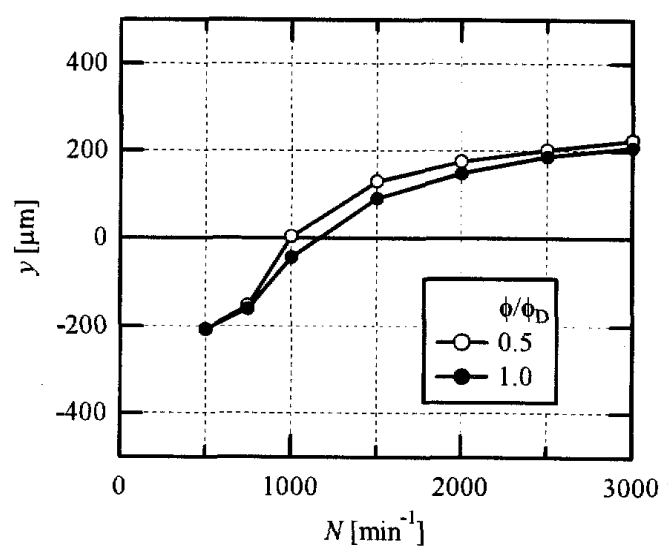

(a) Displacement $y$.

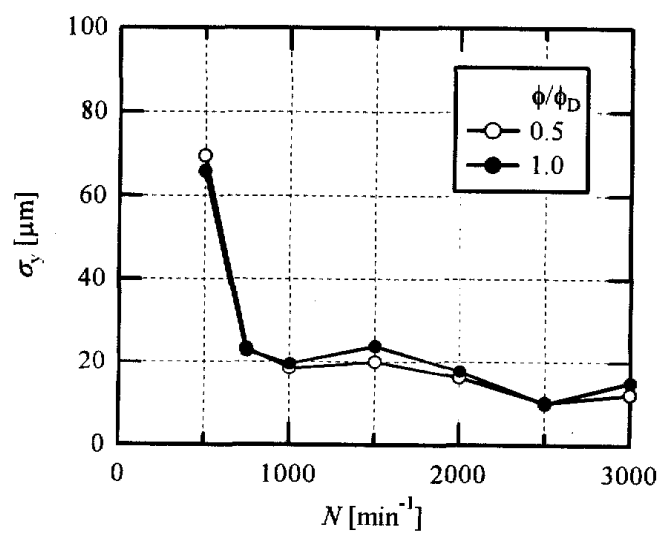

(b) Standard deviation of $y$.

Fig. 8 Whirling motion of impeller for various rotational speeds. 
の運転に支障は出ていない，図9には，羽根車の変位 測定によって得られたふれまわり速度比 $\Omega \omega を$ 示して いる，供試ポンプの $\Omega \omega$ は, 回転速度に低らず一定の 值をとり，その值は約 0.1 となった。この值は, Suzuki ら (の)にれば，流体力が励振的に作用寸る領域であり， 流体力による振動が懸念されるが，本研究では，ふれ まわりの大きさ $\sigma_{\mathrm{y}}$ そのものが小さく自励振動が発生す るまでに至っていない.

6.2 流青変動の羽根車学動人の影霜 前述のよ うに，供試ポンプの羽根車は，ふれまわり運動をしな がら運転されている. そのため, 羽根車には, ふれま わりによる流体力が作用することになる，血液ポンプ は拍動を受ける場合であっても安全に運転されなけれ ばならない, 図10には, 流量変動下における羽根車中 心のケーシング中心からの変位 $\varepsilon$ のふれまわりを標準 偏差ので示している. 強制周波数が大きくなるほど, また，回転速度が途いほど，ふれまわりの大きさを示 すのが大きくなる.よって, 強制周波数の増加と共に, 羽根車のふれまわり振幅が大きくなる。 また, 強制周 波数 $f=1 \mathrm{~Hz}$ を超えると振幅の増加が大きくなる.

これらのことから，流量変動のない場合で注問題な く作動していても, 流量変動時には, 羽根車のふれま わりが大きくなり, 羽根車の運動に影響を与えること がわかった. 特に, 強制周波数が約 $1 \mathrm{~Hz}$ より大きくな るとその影響が顕著になる，但し，本実験の範团内で は発振はしていない.

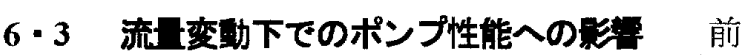

節までで，変動流量によって羽根車のふれまわりが大 きくなることが示された。 ふれまわり運動が大きくな った時のポンプ性能を考慮すべきである. そこで, 動 特性試験では各回転速度での動特性を測定し, 供試ポ ンプの運転限界について調べる，図 11 は動特性試験結 果の一例である. 図には, 回転速度 $3000 \mathrm{~min}^{-1}$ で, 流量

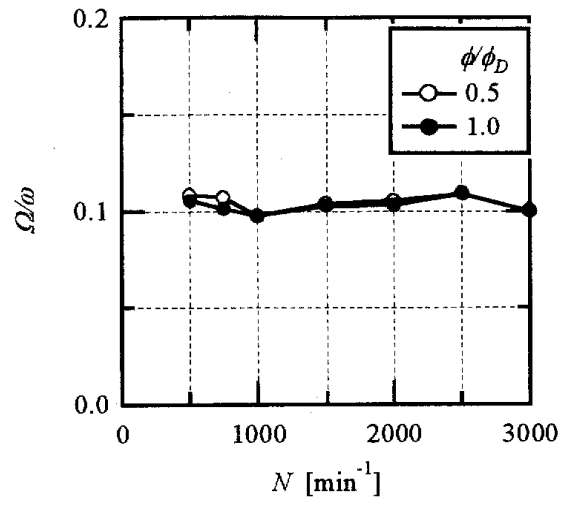

Fig. 9 Whirling ratio of test pump for various rotational speeds.
比 1 および 0.5 の時の, $\operatorname{Re}\left(Z_{p}\right)$ と $\operatorname{Im}\left(Z_{p}\right)$ の強制周波数 $f$ との関係が示されている， $\operatorname{Re}\left(Z_{p}\right)$ は $\mathrm{OHz}$ では静的な $Q-H$ 特性の勾配を示しており， $\operatorname{Re}\left(Z_{p}\right)$ の值が負になる とポンプは不安定になる. 強制周波数 $f$ の增加と共に $\operatorname{Re}\left(Z_{p}\right)$ も増加している. 但し, 低流量域 $\left(\phi \phi_{\mathrm{D}}=0.5\right)$ では, 傾きが極端に小さく, さらに強制周波数 $f \geq 2 \mathrm{~Hz}$ 傾きが逆転し, $\operatorname{Re}\left(Z_{p}\right)<0$ となり, 不安定となっている.

$\operatorname{Im}\left(Z_{p}\right)$ は，ポンプ管路に含まれる液体の慣性, 寸な わち管路効果を表現している。これらは，通常，吐出 し流量や回転速度に依らず，周波数増加之共に増加す る. しかし, 強制周波数 $f>1 \mathrm{~Hz}$ でポンプ内の粘性抵 抗より慣性抵抗の影響が大きくなってポンプの等価長 さが低下寸るため, $\operatorname{Im}\left(Z_{p}\right)$ の $f$ 対する傾きが変化する (12). また, $f<1 \mathrm{~Hz}$ では, 流量によって符号が変化し ている.イナータンスは管路内の液体の慣性であるか ら次の式で表される。

$$
\operatorname{Im}\left(Z_{p}\right)=\frac{\widetilde{p}_{s}-\tilde{p}_{d}}{\widetilde{Q}}=-\frac{1}{g} \frac{L_{e q}}{A}
$$

ここで, $L_{e q}=\int_{x=0}^{L}\left\{A_{0} / A(x)\right\} d x$ はポンプ内の等価管路 長であり，ポンプ内流路の代表流線において， $A_{0}$ は代 表断面積, $A$ は各断面での断面積である. 上式の中で 符号が容易に変化するのは流速 $Q\left(=A v_{m}\right)$ であると考 えられるので, 低流量側 $\left(\phi / \phi_{\mathrm{D}}=0.5\right)$ において, $f<1 \mathrm{~Hz}$ で，傾きが正となるのは，ポンプ内で逆流が起こって いる可能性がある.

通常, 安静にしている人の拍動は 60-90 bpm が一般 的な值と言われる. 図 12 は, 安静時 $60 \mathrm{bpm}$ に相当寸 る強制周波数 $1 \mathrm{~Hz}$ に対して, $\phi 1 \phi_{\mathrm{D}}=0.5$ および 1.0 にお ける羽根車回転速度とレジスタンスの関係を示してい る. 比較のため, 準定常変化を仮定した場合(すなわち,

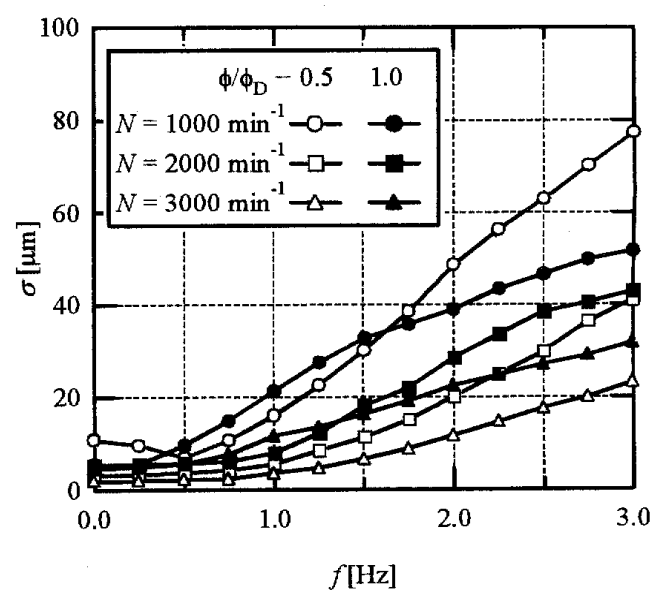

Fig. 10 Whirling motion of impeller for various fluctuating frequencies. 
定常性能曲線から求めた值)も併記されている.

本研究の範囲では, 脈動下に置かれたポンプの性能 は，羽根車回転速度が小さくなるとレジスタンスが低 下し不安定になりやすい状況と言える．また，強制周 波数 $1 \mathrm{~Hz}$ のとき，低回転速度でのレジスタンスは淮定 常值とほとんど差がないため，準定常としての扱いが 可能である，但し，低流量では $\operatorname{Re}\left(Z_{p}\right)$ の值が小さいた め, 前述のイナータンスに関寸る考察のように, 低流 量域では，供試ポンプ内で逆流が起こっている可能性 がある. 生体内では常に抵抗が変化し, 血液ポンプ系 内の流動抵抗が大きくなるような状況が発生しや寸い. よって，血栓や溶血を招く恐机がある逆流の発生は避 けなければならず，改善の余地がある。

本研究の範囲内では, 供試ポンプは, 流量変動下で は，低回転速度での運転や低流量域で，ポンプ性能が

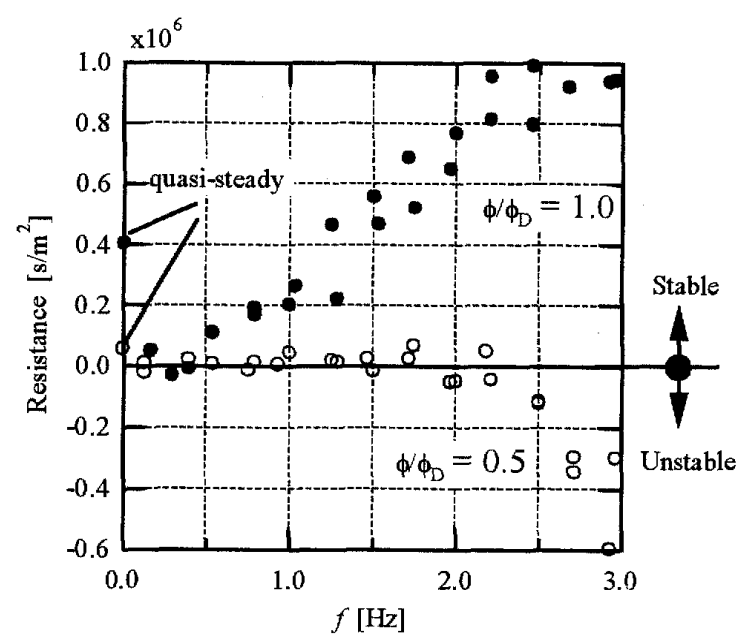

(a) Pump resistance.

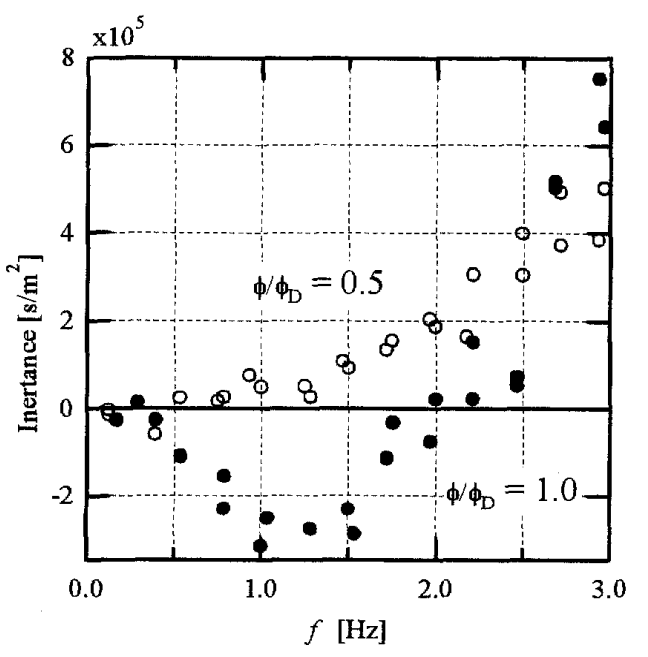

(b) Pump inertance.

Fig. 11 Pump impedance of test pump for various fluctuating frequencies; $N=3000 \mathrm{~min}^{-1}$.
不安定になりや扎とがわかった。これは，軸受反 力低下に依るものとポンプ内の流動状態が関係してい ると考えられる.

ポンプ内部流れ，ふれまわり及び流体力の実測と動 特性の関俕をさらに検討することで不安定要素の把握 が出来, より安全なシステム運用が期待できる.

\section{7. 結 詥}

CSGB 動圧浮上軸受を用いた遠心式血液ポンプの動 的安定性を評価するために, 流量変動の影響について, 羽根車振動とポンプ性能の安定性の二つの観点から検 討を行った，以下に主な結論を述べる.

（1）静特性試験の結果,供試ポンプは, 回転速度 3000 $\mathrm{min}^{-1}$ で流量 $5 \mathrm{~L} / \mathrm{min}$ で全揚程 $2.6 \mathrm{~m}(190 \mathrm{mmHg})$, 最大ポンプ効率法約 0.14 であった。

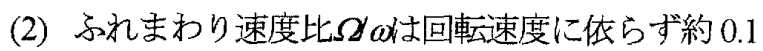
であり，励振的な流体力が作用寸る可能性がある. しかし, 本実験の範囲内では, 発振はしなかった。

(3) 脈動がない状態では, $N \geqq 750 \mathrm{~min}^{-1}$ において，ふ れまわりは小さい, しかし，流量変動下では，ふ れまわりは大きくなる，回転速度が遅いほど，ま た，低流量であるほど，ふれまわりが大きくなる 度合いが大きい。

（4）ポンプ性能は, 流量変動下で, ポンプレジスタン スが増加する. しかし， $\phi / \phi_{D}=0.5$ では，強制周波 数 $f>2 \mathrm{~Hz}$ で, レジスタンスが負となり不安定に なる.

（5）強制周波数 $f=1 \mathrm{~Hz}$ でのポンプレジスタンスは, 羽根車の回転速度が増加すると大きくなるが， $\phi \phi \phi_{D}=0.5$ では, レジスタンスの值は小さく, 羽根

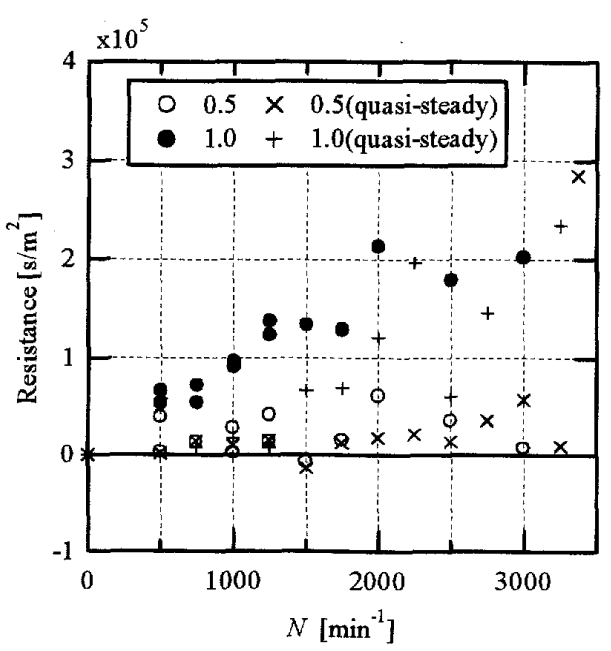

Fig. 12 Pump resistance for various rotational speeds; $f=1$ $\mathrm{Hz}$. 
車の回転速度が大きくても不安定になる可能性が

ある.

以上の事により，羽根車回転速度の低下と流量変動に よって，ふれまわりの増大や，ポンプ性能が不安定な 状態になることが示されたおわりに，本研究を進め るにあたり，有益な助言をいただいた，九州工業大学 工学研究院 宮崎康次准教授, また, 初期の試験装置 製作に尽力いただいた鶴田勇樹氏に心からの感謝の意 を表します。

\section{文献}

(1) Yoshino, Y. and Akamatsu, T., Performance and Characteristics of Magnetically Suspended Centrifugal Blood Pump, Trans. JSME, Ser. B, Vol. 60, No. 579 (1994), pp. 3687-3692.

(2) Asama, J., et al., A Compact Highly Efficient and Low Hemolytic Centrifugal Blood Pump with a Magnetically Levitated Impeller, Artificial Organs, Vol. 30, No. 3 (2006), pp. 160-167.

(3) Asama, J., et al., Dynamic Characteristics of a Magnetically Levitated Impeller in a Centrifugal Blood Pump, Artificial Organs, Vol. 31, No. 4 (2007), pp. 301-311.

(4) Ochiai, Y., et al., In Vivo Hemodynamic Performance of the Cleveland Clinic CorAide Blood Pump in Calves, The Annual Thoracic Surgery, Vol. 72 (2001), pp. 747-52.
(5) Chung, M., et al., Experimental Determination of Dynamic Characteristics of the VentrAssist Implantable Rotary Blood Pump, Artificial Organs, Vol. 28, No. 12 (2004), pp. 1089-1094.

(6) Suzuki, T., et al., The Rotordynamic Fluid Forces on an Artificial Heart Pump Impeller in Whirling Motion, Trans. JSME. Ser. B, Vol. 73, No. 725 (2007), pp. 205-212.

(7) Anderson, D.A., Blade, R.J. and Stevans, W., Response of a Radial-Bladed Centrifugal Pump to Sinusoidal Disturbances for Noncavitating Flow, NASA TN D-6556 (1971).

(8) Kawata, Y., et al., System Instability Caused by the Dynamic Behavior of a Centrifugal Pump at Partial Operation, JSME International Journal, Vol. 30, No, 260 (1987), pp. 271-278.

(9) Ng, S.L. and Brennen, C., Experiments on the Dynamic Behavior of Cavitating Pumps, Trans. $A S M E$, J. Fluids Eng., Vol. 100 (1978), pp. 166-176.

(10) Nakamura, Y., et al, Experimental study of Dynamic Characteristics of a Centrifugal Blood pump with a Conical Spiral Groove Bearing for a Ventricular Assist Device, 5th Joint ASME / JSME Fluids Engineering Conference, (2007), FEDSM2007-37235.

(11) Muijderman, E.A., Analysis and design of Spiral-Groove Bearings, ASME J. Lubric. Tech., Vol. 89 (1967), pp. 291-306.

(12) Sano, M., Pressure Pulsation in Turbo-Pump Piping System (1st Report, Experiments on the Natural Frequencies of the Liquid Column of Centrifugal Pump Piping Systems), Trans. JSME., Ser. B, Vol.49, No. 440(1983), pp. 828-836. 